\title{
Sociodemographic Correlates of Practice towards Oral Hygiene among University Students: A Cross-sectional Insight
}

\author{
Muhammad Zahid Iqbal', Khaleda Omar', Abdul Nazer Ali', Mohd Baidi Bahari', Muhammad Shahid Iqbal 2,** \\ 'Department of Clinical Pharmacy and Pharmacy Practice, Faculty of Pharmacy, AIMST University, Bedong, Kedah Darul Aman, MALAYSIA. \\ 2Department of Clinical Pharmacy, College of Pharmacy, Prince Sattam bin Abdulaziz University, Al-kharj, SAUDI ARABIA.
}

\begin{abstract}
Objectives: This study aimed to determine sociodemographic correlates of practice towards oral hygiene $(\mathrm{OH})$ among university students in a private university. Methods: A cross-sectional study was performed among university students in Malaysia using a prevalidated questionnaire. The convenient stratified sampling method was adopted to recruit participants from four main faculties of a private university. The Statistical Package for Social Science (SPSS) Version 24.0 was used to analyze the data. Univariate and multivariate analyses were performed to determine the correlates of practice of $\mathrm{OH}$ among the study participants. Results: Out of a total of 324 participants, female students had far-good practice towards $\mathrm{OH}$ than males. The final year students showed better $\mathrm{OH}$ practice than the pre-final years. Among the studied races, the Chinese students had the highest percentage of adequate practice than the rest. Overall, this study found that most of the students had fair to good practice towards $\mathrm{OH}$.
\end{abstract}

Conclusion: Multiple logistic regression analyses showed that statistically significant differences $(p<0.05)$ were present among the six demographic variables. The current study found that age groups, race, faculty, year of education, parents' education, and healthcare professionals in the family were the sociodemographic correlates of practice towards $\mathrm{OH}$ among the university students in Malaysia.

Key words: Oral hygiene, OH, Practice, Private, University students.

\section{Correspondence}

Dr. Muhammad Shahid Iqbal

Department of Clinical Pharmacy, College of Pharmacy, Prince Sattam bin

Abdulaziz University, Al-kharj, 11942, SAUDI ARABIA.

Phone no: +966-53-7014420

Email: drmmsiqbal@gmail.com

DOI: 10.5330/ijpi.2020.3.71

\section{INTRODUCTION}

Oral health is a vital aspect for everyone's life either children, adults, or elders. Furthermore, it is of significant importance when it comes to teenagers and students. ${ }^{1,2}$ Students despite having a busy student life cannot neglect the importance of oral health as after completing their studies, they would be role models to the community especially in their families. Additionally, having appropriate oral hygiene $(\mathrm{OH})$ practice is imperative to encourage others to take care of their oral health. ${ }^{3,4}$

Furthermore, precise education and awareness about routine $\mathrm{OH}$ are the most important factors to be considered among the students. ${ }^{5,6}$ Increasing the awareness about good practice towards $\mathrm{OH}$ can make individuals grasp more information about a healthy lifestyle which could greatly help in preventing oral diseases and maintaining $\mathrm{OH} .{ }^{1-6}$ Diet always plays a significant role in an apt $\mathrm{OH}$ and overall good dental care. Over-consumption of soft drinks often leads to various oral diseases and prolonged complications. ${ }^{7,8}$ In maintaining $\mathrm{OH}$, prevention and management of various dental diseases like dental caries are also important to consider. The dental caries is always tagged with a high cost of treatment and if left untreated could lead to oral pain and teeth loss which eventually affects the oral quality of life. ${ }^{7-10}$ Other risk factors in maintaining $\mathrm{OH}$ include the frequent use of tobacco and the consumption of alcohol. ${ }^{11,12}$

There are many ways to obtain good $\mathrm{OH}$ and one of the main practices that should be routinely done is regular brushing of the teeth. Students may have bad oral health practices due to their busy teaching and learning schedule. ${ }^{13-15}$ Insufficient time may cause them not to regularly brush their teeth and neglecting other important $\mathrm{OH}$ practices. Although antimicrobial mouthwashes can help reduce numerous oral infections, caries and plaque which can lead to gingivitis and gum diseases. ${ }^{14-16} \mathrm{But}$ yet continuity in adopting good practices to attain $\mathrm{OH}$ is recommended by the American Dental Association (ADA). ${ }^{13}$ Regular and gentle brushing of the tongue can also help in removing various germs and maintain freshens of the breath. ${ }^{14}$ According to the World Health Organization (WHO), oral diseases could be significantly decreased by practicing good $\mathrm{OH}$ and addressing the common risk factors. ${ }^{16}$ The common risk factor for bad $\mathrm{OH}$ could be due to excessive use of soft drinks, sugary and dairy products, alcohol consumption and inappropriate teeth brushing techniques. ${ }^{10-12,17}$ The current study aimed to assess $\mathrm{OH}$ practices and its predictors among university students in a private university in Malaysia.

\section{MATERIALS AND METHODS}

This cross-sectional study was conducted among pre-final and final year students from the four faculties i.e. medicine, pharmacy, business and biotechnology at a private medical university. The current study was carried out over nine months (September 2017 to May 2018) in which data collection and the analysis of the data were done. Stratified convenient sampling technique was adopted to achieve the sample size of this research. The sample size of 350 students was collected based on the student population in the pre-final and final year from each faculty.

The data were collected from the four faculties regarding various variables like gender, age groups, race, faculty, year of education, residence, parents' education and healthcare professionals in family. For avoiding any bias, the sample was obtained by random recruitment of pre-final and final year students from each faculty. Only those students were included in the study who were willing to participate voluntarily and gave consent. 
This study was conducted through a self-administered and validated research questionnaire. The preliminary questionnaire was prepared after an in-depth literature review and a modified version was developed and later validated by experienced professionals in a related field. The questionnaire consisted of diverse statements in the dichotomous form "Yes" or "No" based on their practice about $\mathrm{OH}$ in daily life. A score of 1 was credited to the correct answer and 0 to an incorrect answer. The criteria for evaluation were defined according to previous studies ${ }^{18-20}$ where $<5$ correct answers show poor practice, 6-7 correct answers show fair practice and $>7$ correct answers show good practice among the university students regarding $\mathrm{OH}$. All aspects of the study protocol were authorized by the concerned university ethical committee and all of the requirements were met before the start of the study.

\section{Statistical Analyses}

Categorical variables were presented as frequencies and percentages and means and standard deviations were calculated for the continuous variables. Logistic regression analysis was used to analyze the

Table 1: Demographic characteristics of study participants $(n=324)$.

\begin{tabular}{lc}
\hline \multicolumn{1}{c}{ Variable } & N (\%) \\
\hline Gender & \\
Male & $90(27.8)$ \\
Female & $234(72.2)$ \\
Age groups & \\
18-20 years & $52(16.1)$ \\
$21-25$ years & $252(77.7)$ \\
$>$ 25 years & $20(6.2)$ \\
Race & \\
Malay & $12(3.7)$ \\
Chinese & $211(65.2)$ \\
Indian & $95(29.3)$ \\
Others & $6(1.8)$ \\
Faculty & \\
Pharmacy & $118(36.4)$ \\
Medicine & $81(25.0)$ \\
Biotechnology & $67(20.6)$ \\
Business & $58(18.0)$ \\
Year of education & $107(33.1)$ \\
Pre-final & $217(66.9)$ \\
Final & \\
Residence & $169(52.2)$ \\
Hosteller & $155(47.8)$ \\
Non- Hosteller & \\
Parents' education & $216(66.7)$ \\
$<$ Primary & $108(33.3)$ \\
Pre-university & \\
University & \\
Healthcare professionals in family & \\
No & \\
\hline & \\
\hline
\end{tabular}

sociodemographic correlates of practices towards $\mathrm{OH}$ among the university students. Factors found significant in univariate analysis, were included in multivariate logistic regression to estimate the odds ratios (ORs) with $95 \%$ confidence intervals (CIs). $P$-value $<0.05$ was considered statistically significant.

\section{RESULTS}

Table 1 shows different demographic details of the study participants like gender, age groups, race, faculty, year of education, residence, parents' education and healthcare professionals in family. A total of 324 students were involved in the study. A total of 324 (72.2\%) were females and $90(27.8 \%)$ were the males. The participation from each faculty was pharmacy 118 (36.4\%), medicine 81 (25.0\%), biotechnology 67 (20.6\%) and business $58(18.0 \%)$.

Table 2 represents the practice score of the study participants with the percentage. The practice scores are categorized as poor, fair and good. There were a total of 10 diverse questions regarding $\mathrm{OH}$ practice were asked from the study participants.

Table 2: Practice response to oral hygiene among students.

\begin{tabular}{|c|c|c|c|}
\hline \multirow[t]{2}{*}{ Variables } & \multicolumn{3}{|c|}{ Practice towards $\mathrm{OH}(\mathrm{N} \%)$} \\
\hline & Poor & Fair & Good \\
\hline \multicolumn{4}{|l|}{ Gender } \\
\hline Male & $11(12.2)$ & 64 (71.1) & 15 (16.7) \\
\hline Female & $18(7.7)$ & $173(73.9)$ & $43(18.4)$ \\
\hline \multicolumn{4}{|l|}{ Age groups } \\
\hline $18-20$ years & $16(30.8)$ & $25(48.1)$ & $11(21.1)$ \\
\hline $21-25$ years & $27(10.7)$ & $163(64.7)$ & $62(24.6)$ \\
\hline$>25$ years & $3(15.0)$ & $7(35.0)$ & $10(50.0)$ \\
\hline \multicolumn{4}{|l|}{ Race } \\
\hline Malay & $3(25.0)$ & $5(41.7)$ & $4(33.3)$ \\
\hline Chinese & $19(9.0)$ & $148(70.2)$ & $44(20.8)$ \\
\hline Indian & $12(12.6)$ & $65(68.5)$ & 18 (18.9) \\
\hline Others & $1(16.7)$ & $3(50.0)$ & $2(33.3)$ \\
\hline \multicolumn{4}{|l|}{ Faculty } \\
\hline Pharmacy & $9(7.6)$ & $98(83.1)$ & $11(9.3)$ \\
\hline Medicine & $9(11.1)$ & $60(74.1)$ & $12(14.8)$ \\
\hline Biotechnology & $5(7.5)$ & $52(77.6)$ & $10(14.9)$ \\
\hline Business & $5(8.6)$ & $28(48.3)$ & $25(43.1)$ \\
\hline \multicolumn{4}{|l|}{ Year of education } \\
\hline Pre-final & $18(10.7)$ & $126(74.6)$ & $25(14.7)$ \\
\hline Final & $10(6.4)$ & $112(72.3)$ & $33(21.3)$ \\
\hline \multicolumn{4}{|l|}{ Residence } \\
\hline Hosteller & $17(7.9)$ & $170(78.7)$ & $29(13.4)$ \\
\hline Non- Hosteller & $12(11.1)$ & $68(63.0)$ & $28(25.9)$ \\
\hline \multicolumn{4}{|l|}{ Parents' education } \\
\hline$<$ Primary & $97(84.3)$ & $7(6.1)$ & $11(9.6)$ \\
\hline Pre-university & $99(82.5)$ & $9(7.5)$ & $12(10.0)$ \\
\hline University & $59(66.3)$ & $13(14.6)$ & $17(19.1)$ \\
\hline \multicolumn{4}{|c|}{ Healthcare professionals in family } \\
\hline Yes & $7(6.5)$ & $25(23.4)$ & $75(70.1)$ \\
\hline No & $36(16.6)$ & 41 (18.9) & $140(64.5)$ \\
\hline
\end{tabular}


Table 3 denotes the correlates (predictors) of practice to $\mathrm{OH}$ with univariate analysis and multivariate regression models. In the univariate analysis results, a total of seven variables were found statistically significant. In multivariate logistic regression analysis, six variables were found to be statistically significant.

\section{DISCUSSION}

This study showed that the majority of the students from each faculty had fair practice about $\mathrm{OH}$. According to the results obtained, students from pharmacy 98 (83.1\%), medicine 60 (74.1\%), biotechnology 52 (77.6\%) and business $28(48.3 \%)$ showed a fair practice of $\mathrm{OH}$. In comparison among faculties, almost all of the participants had fair to good practices about $\mathrm{OH}$. The medicine faculty students had better practice for $\mathrm{OH}$ with (COR 3.543; $p=0.031$ ) than the biotechnology students (COR 2.673; $p$ $=0.021)$. The highest percentage that showed good practice regarding $\mathrm{OH}$ was from the business faculty students. In opposition, the least good practices were observed from the students of faculty of biotechnology. From the year of education variable, the highest percentage of students that are having good practice towards their oral health was the final year students.

In univariate analysis, our study results reported significant differences $(p<0.05)$ in gender, age groups, race, faculty, year of education, parents' education and healthcare professionals in family. In gender (COR $1.261 ; p=0.049)$ where only $15(16.7 \%)$ males and $43(18.4 \%)$ female students had good practices towards $\mathrm{OH}$. This study reported that there was a statistically significant association seen among males and females regarding the practice of $\mathrm{OH}$. From the results obtained, it was evident that females had a good practice of $\mathrm{OH}$ at a larger percentage than male students. Appropriate education and awareness about $\mathrm{OH}$ can improve students' $\mathrm{OH}$ practices. Another study performed among students in Turkey also confirmed that oral and dental good health practice among students can easily be enhanced with increasing their awareness about

Table 3: Practice correlates of oral hygiene.

\begin{tabular}{|c|c|c|c|c|}
\hline \multirow[t]{2}{*}{ Variables } & \multicolumn{2}{|c|}{ Univariate analysis } & \multicolumn{2}{|c|}{ Multivariate analysis } \\
\hline & OR $(95 \% \mathrm{Cl})$ & $P$-Value & OR $(95 \% \mathrm{Cl})$ & $P$-Value \\
\hline \multicolumn{5}{|l|}{ Gender } \\
\hline Male & Referent & & Referent & \\
\hline Female & $1.261(0.39-4.57)$ & 0.049 & $1.016(0.37-3.25)$ & 0.436 \\
\hline \multicolumn{5}{|l|}{ Age groups } \\
\hline $18-20$ years & Referent & & Referent & \\
\hline 21-25 years & $5.365(3.22-6.84)$ & 0.001 & $3.543(2.23-4.71)$ & 0.021 \\
\hline$>25$ years & $8.542(5.54-9.97)$ & 0.001 & $6.762(3.13-6.82)$ & 0.041 \\
\hline \multicolumn{5}{|l|}{ Race } \\
\hline Malay & Referent & & Referent & \\
\hline Chinese & $4.452(2.25-7.54)$ & 0.001 & $3.132(1.43-5.14)$ & 0.034 \\
\hline Indian & $1.421(0.65-2.11)$ & 0.423 & - & - \\
\hline Others & - & - & - & - \\
\hline \multicolumn{5}{|l|}{ Faculty } \\
\hline Pharmacy & Referent & & Referent & \\
\hline Medicine & $3.543(2.92-5.31)$ & 0.031 & $2.011(1.41-4.65)$ & 0.367 \\
\hline Biotechnology & $2.673(1.96-4.29)$ & 0.045 & $1.257(1.78-3.54)$ & 0.051 \\
\hline Business & $3.433(2.87-6.67)$ & 0.021 & $2.213(1.37-4.35)$ & 0.048 \\
\hline \multicolumn{5}{|l|}{ Year of education } \\
\hline Pre-final & Referent & & Referent & \\
\hline Final & $3.456(2.12-8.76)$ & 0.005 & $2.211(1.82-4.72)$ & 0.045 \\
\hline \multicolumn{5}{|l|}{ Residence } \\
\hline Hosteller & Referent & & & \\
\hline Non-hosteller & $0.741(0.52-2.19)$ & 0.215 & & \\
\hline \multicolumn{5}{|l|}{ Parents' education } \\
\hline$<$ Primary & Referent & & Referent & \\
\hline Pre-university & $1.439(0.43-2.61)$ & 0.639 & - & - \\
\hline University & $3.458(2.86-8.14)$ & 0.007 & $2.489(1.25-6.82)$ & 0.032 \\
\hline \multicolumn{5}{|c|}{ Healthcare professionals in family } \\
\hline Yes & Referent & & Referent & \\
\hline No & $3.273(2.11-7.29)$ & 0.001 & $2.531(1.49-5.52)$ & 0.011 \\
\hline
\end{tabular}

OD = Odds Ratio, 95\% CI = 95\% Confidence Interval 
Iqbal, et al:: Sociodemographic Correlates of Practice towards $\mathrm{OH}$ among University Students

$\mathrm{OH} .{ }^{21}$ According to another study finding, it was seen that the students' oral health awareness was significantly improved in their final years. ${ }^{22}$

There was a non-significant effect of the place of living observed among the study participants' regarding $\mathrm{OH}$. From the study results, it was shown that hostellers had a higher percentage of fair and good practices of $\mathrm{OH}$ than non-hostellers. A study done by Astrom et al. about oral health behaviors at the age of 15-35 years reported that a better oral health practice was noted among the female participants. The reason behind could be that females often present more attentiveness in maintaining a well-mannered and well-dressed appearance. ${ }^{23}$ Similar to our and their findings, another study also had similar results that the oral and dental healthcare of female students were better than the male students. ${ }^{21}$ Another study findings also corroborate to our results that oral behavior of female students towards better dental care practice was higher than the male students. ${ }^{24}$

Statistically, no significant difference was seen among age groups regarding the $\mathrm{OH}$ practice of the study respondents. From the results obtained, it was noted that the percentage of good $\mathrm{OH}$ practice among the students increased with age. In univariate analysis findings, parents' education was also found as statistically significant between primary or low-level education and university levels. For university-level education (COR 3.458; $p=0.007$ ) were observed which clearly showed that statistically significant differences were present among both groups regarding $\mathrm{OH}$ practices.

In this study, regarding the different races of the study students, mix findings were observed about fair and good $\mathrm{OH}$ practice. The reason behind could be that there was a large difference present regarding the total number of respondents from each race, which made it unable to reflect on the actual practice of the respondents from all of the races. According to another study, there was also a substantial cultural difference existed in oral health practice among students from different race and cultural backgrounds. ${ }^{1}$

In our study, correlates of good practice of $\mathrm{OH}$ were obtained by controlling or adjusting confounders using the multivariate logistic regression model. In logistic regression analysis, it was inferred that age groups, race, faculty, year of education, parents' education and healthcare professionals in the family were the pure correlates (determinants) of practice towards $\mathrm{OH}$ among university students. The highest odds for the variables i.e. the age groups " $>25$ years" (AOR6.762; $p=0.041$ ), race "Chinese" (AOR 3.132; $p=0.034$ ), faculty "business" (AOR 2.213; $p=0.048$ ), year of education (AOR 2.211; $p=0.045$ ), parents' education "university" (AOR 2.489; $p=0.032)$ and the healthcare professionals in the family (AOR $2.531 ; p=0.011$ ) were reported when adjusted for the other studied demographic variables.

The results of the current study may be skewed due to a significantly higher number of female respondents than the males, a higher number from age group (21-25 years old), a higher number of single students and also higher number of pharmacy students. In terms of ethnicity, there was a difference in participants' size from each faculty, which may lead to some bias in the obtained results. Like many other similar studies, this was a cross-sectional study whereby its generalizability was limited by the size of the studied population. Hence, the results cannot be projected to the entire country.

\section{CONCLUSION}

The study reported that age groups, race, faculty, year of education, parents' education and healthcare professionals in the family were the correlates (determinants) of practice towards $\mathrm{OH}$ among university students. This study was novel among its type as there was no earlier study reported regarding correlates of practice of $\mathrm{OH}$ among university students in Malaysia.

\section{ACKNOWLEDGEMENT}

The authors would like to thank the Deanship of Scientific Research at Prince Sattam bin Abdulaziz University, Alkharj, Saudi Arabia, for the support in the publication of this manuscript. The authors would also like to express their sincere gratitude to all of the participants involved in this study in any capacity.

\section{CONFLICT OF INTEREST}

The authors declare no conflict of interest.

\section{ABBREVIATIONS}

OH: Oral Hygiene; WHO: World Health Organization; SPSS: Statistical Package for Social Sciences; CI: Confidence Interval; OR: Odds Ratio; COR: Crude Odds Ratio; AOR: Adjusted Odds Ratio.

\section{REFERENCES}

1. Kawamura M, Wright FA, Declerck D, Freire MC, Hu DY, Honkala E, et al. An exploratory study on cultural variations in oral health attitudes, behaviour and values of freshman (first-year) dental students. Int Dent J. 2005;55(4):205-11.

2. Al-Ansari J, Honkala E, Honkala S. Oral health knowledge and behavior among male health sciences college students in Kuwait. BMC Oral Health. 2003;3(1):2.

3. Al-Omiri MK, Al-Wahadni AM, Saeed KN. Oral health attitudes, knowledge and behavior among school children in North Jordan. J Dent Educ. 2006;70(2):17987.

4. Vellappally S, Jacob V, Smejkalová J, Sriharsha P, Kumar V, Fiala Z. Tobacco habits and oral health status in selected Indian population. Cent Eur J Public Health. 2008;16(2):77-84.

5. Kawamura M, Yip HK, Hu DY, Komabayashi T. A cross-cultural comparison of dental health attitudes and behavior among freshman dental students in Japan, Hong-Kong and West China. Int Dent J. 2001;51(3):159-63.

6. Reddy V, Bennadi D, Gaduputi S, Kshetrimayum N, Siluvai S, Reddy CV. Oral health related knowledge, attitude and practice among the pre-university students of Mysore city. J Int Soc Prev Community Dent. 2014;4(3):154-8.

7. Petersen $\mathrm{P}$, Kwan S. World Health Organization global oral health strategies for oral health promotion and disease prevention in the twenty-first century. Prävention und Gesundheitsförderung. 2009;4(2):100-4.

8. Mishra MB, Mishra S. Sugar-sweetened beverages: General and oral health hazards in children and adolescents. Int J Clin Pediatr Dent. 2011;4(2):119-23.

9. Tinanoff N, Palmer CA. Dietary determinants of dental caries and dietary recommendations for preschool children. J Public Health Dent. 2000;60(3):197206.

10. Tinanoff N. Association of diet with dental caries in preschool children. Dent Clin North Am. 2005;49(4):725-37.

11. Thavarajah R, Rao A, Raman U, Rajasekaran ST, Joshua E, Hemalatha R, et al Oral lesions of 500 habitual psychoactive substance users in Chennai, India. Arch Oral Biol. 2006;51(6):512-9.

12. Rooban T, Vidya KM, Joshua E, Rao A, Ranganathan S, Rao UK, et al. Tooth decay in alcohol and tobacco abusers. J Oral Maxillofac Pathol. 2011;15(1):14-21.

13. American Dental Association. Seven common mistakes and how to fix them. 2020. https://www.prnewswire.com/news-releases/ada-releases-new-brushing-tips-for-the-new-year-300386535.html

14. Cunha-Cruz J, Huebner CE, Ludwig S, Dysert J, Mitchell M, Allen G, et al. Everybody brush! Consumer satisfaction with a tooth decay prevention program. Front Public Health. 2017;5:264.

15. Creeth JE, Kelly SA, González-Cabezas C, Karwal R, Martinez-Mier EA, Lynch RJM, et al. Effect of toothbrushing duration and dentifrice quantity on enamel remineralisation: An in situ randomized clinical trial. J Dent. 2016;55:61-7.

16. World Health Organization. Bulletin of the World Health Organization, Prevention is better than treatment https://www.who.int/bulletin/volumes/93/9/15-020915/ en/

17. Rooban T, Mishra G, Elizabeth J, Ranganathan K, Saraswathi TR. Effect of habitual areca nut chewing on resting whole mouth salivary flow rate and $\mathrm{pH}$. Indian J Med Sci. 2006;60(3):95-105.

18. Wanyama SP, Marco S, Kariuki MM. Knowledge, attitude and practice of eye diseases in children among paediatricians in Kenya. J Ophth East Cent South Africa. 2015;19(1):22-6.

19. Considine J, Botti M, Thomas S. Design, format, validity and reliability of multiple choice questions for use in nursing research and education. Collegian. 2005;12(1):19-24.

20. Kazi AM, Khalid W. Questionnaire designing and validation. J Pak Med Assoc. 
Iqbal, et al:: Sociodemographic Correlates of Practice towards OH among University Students

2012;62(5):514-6.

21. Peker I, Alkurt MT. Oral health attitudes and behavior among a group of Turkish dental students. Eur J Dent. 2009;3(1):24-31.

22. Yildiz S, Dogan B. Self reported dental health attitudes and behaviour of dental students in Turkey. Eur J Dent. 2011;5(3):253-9.
23. Astrøm AN. Stability of oral health-related behaviour in a Norwegian cohort between the ages of 15 and 23 years. Community Dent Oral Epidemiol. 2004;32(5):354-62.

24. Rahman B, Al Kawas S. The relationship between dental health behavior, oral hygiene and gingival status of dental students in the United Arab Emirates. Eur J Dent. 2013;7(1):22-7.

Article History: Submission Date : 30-07-2020; Revised Date : 19-08-2020; Acceptance Date : 14-09-2020.

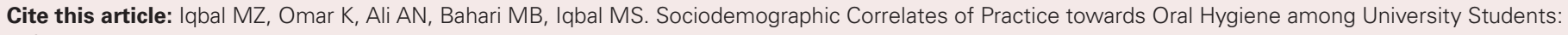
A Cross-sectional Insight. Int. J. Pharm. Investigation, 2020;10(3):402-6. 